\title{
ANALISIS STRUKTURAL TERHADAP INFORMASI KITAB SUCI: MITIGASI BENCANA HYDROMETEOROLOGI DARI PENGALAMAN NABI YUSUF AS
}

\author{
Structural Analysis of Scripture Information: Hydrometeorological Disaster \\ Mitigation from the Experience of Prophet Yusuf As
}

\author{
Momon Sudarma \\ MAN 2 Kota Bandung \\ Jalan Raya Cipadung No. 57, Cipadung, Kecamatan Cibiru \\ Kota Bandung 40615 \\ E-mail:momonsudarma@yahoo.com
}

\begin{abstract}
The Quran is one of the sources of scripture that can be used as a source of information. From an Islamic perspective, the Quran is not only a source of religious ethics but also a source of ethics and behavioral guidelines in responding to the environment and life. In it, there are rules, stories, or guidelines that can be used as guidelines in formulating a code of life and life, including in responding to disasters. The story of Yusuf As (Joseph) provides information code related to mitigation of hydrometeorology disaster. This discourse, trying critically, conducts a library study to the verses of mitigates, especially in the story of Joseph As. In this finding, there are four constructed strategic mitigation measures; (1) data and information collection, both local and scientific knowledge, (2) building information and communication networks, (3) professional staffing, and (4) developing strategic programs.
\end{abstract}

Keywords: Joseph, mitigation, hydrometeorology

\begin{abstract}
Abstrak
Al-Quran adalah salah satu Kitab Suci yang bisa dijadikan sumber informasi. Dalam perspektif Islam, Al-Quran bukan saja sumber etika beragama, melainkan juga sumber etika dan panduan perilaku dalam merespon lingkungan dan kehidupan. Didalamnya terdapat aturan, kisah, atau pedoman yang dapat dijadikan pedoman acuan dalam merumuskan kode etik hidup dan kehidupan, termasuk dalam merespon bencana. Kisah Nabi Yusuf As, memberikan kode informasi dalam kaitannya dengan mitigasi bencana hydrometeorologi. Wacana ini, berusaha secara kritis, melakukan studi kepustakaan, terhadap ayat-ayat mitigasi, khususnya dalam Kisah Yusuf As. Dalam temuan ini, terkonstruksi empat langkah strategis mitigasi, yaitu (1) pengumpulan data dan informasi, baik local maupun scientific knowledge, (2) membangun jaringan informasi dan komunikasi, (3) staffing yang professional, dan (4) menyusun program strategis.
\end{abstract}

Kata kunci: kisah Yusuf, kekeringan, Informasi Kitab Suci, mitigasi

\section{PENDAHULUAN}

Bencana bisa disebabkan karena perubahan faktor iklim dan cuaca, atau disebut juga hydrometeorology hazard. Khusus untuk negara-negara yang ada di khatulistiwa, 
bencana sejenis ini, merupakan salah satu musibah yang potensial terjadi pada setiap waktu

Dalam konsep keilmuan, ada yang disebut faktor-faktor perubahan iklim dan cuaca. Faktor-faktor dimaksud, yaitu keawanan, angin, kelembaban dan tekanan udara, serta curah hujan. Faktor-faktor iklim dan cuaca dimaksud, berbeda antara satu waktu dengan waktu lainnya, antarsatu daerah dengan daerah lainnya, termasuk akan memberikan dampak yang berbeda terhadap daerah yang tertimpanya. Pada saat ada perbedaan intensitas atau frekuensi dari setiap variabel tersebut, kemudian akan berdampak pada kondisi dan keadaan alam di daerah tersebut. Jika musim hujan tiba, maka bencana banjir, longsor dan erosi, serta luapan sungai akan menjadi potensi bencana bagi daerah-daerah tertentu. Buntut dari bencana itu, selain menyisakan puingpuing kerugian, kekurangan air bersih, dan kerusakan lingkungan, akan menghantui kawasan yang terkena bencana di musim hujan. Kemudian, jika musim kemarau tiba, daerah tersebut pun hendaknya waspada dengan ragam potensi bencana yang mengintai. Mulai kekeringan, gagal panen, suhu yang tinggi, kebakaran hutan, kelaparan dan dehidrasi. Buntut dari bencana itu belum berhenti, karena potensial pula ada bencana susulan lainnya, seperti kekurangan pangan dan kemiskinan.

Bencana hydrometeorology ini, termasuk bencana yang sangat dekat dengan kehidupan manusia, dan termasuk kategori sering terjadi dalam kehidupan manusia. Tanggungjawab kita adalah melakukan kajian mengenai cara menghadapi bencana hydrometeorology, langkah praktis dan strategis dalam menghadapi ancaman bencana, dan/atau kegiatan rehabilitasi pasca bencana dari perspektif al-Quran.

Tulisan ini dirmaksudkan untuk menganalisis gagasan mitigasi bencana dari pengalaman Nabi Yusuf As, sebagaimana dikisahkan dalam Kitab Suci Al-Quran. Penelitian ini, mengacu pada dua asumsi. Pertama, menurut catatan sejarah dan kebudayaan Islam, Nabi Yusuf As, merupakan salah satu nabi dan rasul Allah yang berhasil secara gemilang dalam mengatasi bencana kekeringan dan ancaman kelaparan, dan bahkan dinyatakan sebagai bendahara atau menteri keuangan kerajaan yang sukses. Kedua, Al-Quran memiliki posisi sentral dalam studi Islam (Ma'arif, 1991; Shihab, 1991). Kehadiran Al-Quran sebagai petunjuk (hudan), juga memiliki fungsi sebagai sumber ilmu atau inspirasi dalam pengembangan ilmu pengetahuan (Al-Alusi, 2014; Nasr, 1997) Secara tegas Al-Quran memberikan pesan bahwa dalam kisah-kisah terdahulu terdapat pelajaran yang bisa dipetik oleh kalangan orang berpikir (ulul albab). Sungguh, pada kisah-kisah mereka itu terdapat pengajaran bagi orang yang mempunyai akal. (Al-Quran) itu bukanlah cerita yang dibuat-buat, tetapi membenarkan (kitab-kitab) yang sebelumnya, menjelaskan segala sesuatu, dan (sebagai) petunjuk dan rahmat bagi orang-orang yang beriman (QS. Yusuf, 12:111).

Berdasarkan asumsi tersebut, dapat ditarik inspirasi bahwa kisah-kisah yang ada di dalam kitab suci Al-Quran memiliki pelajaran yang perlu digali, dirumuskan dan dikonstruksi, khususnya oleh mereka-mereka yang berakal (ulil albab). Untuk menggali inspirasi informasi kitab suci itu perlu dilakukan dengan memanfaatkan pendekatan keilmuan yang dimiliki manusia. Dalam studi Agama, Ali AM (1991) berpendapat 
bahwa perlu ada upaya dari kalangan ilmuwan untuk bisa menggunakan ragam model pendekatan ilmu, termasuk pendekatan yang dikembangkan orang Barat. Salah satu pendekatan yang dapat diterapkan dalam menganalisis informasi dalam Al-Quran adalah pendekatan strukturalisme.

Strukturalisme adalah salah satu model dalam menganalisis bahasa, khususnya sastra. Seni sastra dalam hal ini, ada tiga jenis, yakni sastra bahasa, non-literer (arsiktur, kaligrafi), dan customer art seperti pakaian, atau makanan. Dalam konteks ini, AlQuran adalah fakta sosial dalam bentuk bahasa. Oleh karena itu, dalam mengkaji AlQuran dapat digunakan pendekatan kebahasaaan, salah satu diantaranya adalah strukturalisme.

\section{PEMBAHASAN}

Model analisis strukturalisme pernah dikemukakan oleh Ferdinand de Saussure (1857-1913). Pendekatan ini, memokuskan kajian untuk mengembangkan model studi sistematis terhadap ciri struktural dan fungsional bahasa yang tumbuhkembang di masyarakat (Widodo, 2020). Dari sudut pandang ini, maka sebuah bahasa, seperti yang tampak dalam Kitab Suci Al-Quran, akan dianalisis menjadi dua komponen utama, yakni tanda (signified) dan penanda (signifier). Lebih lanjut, Sembodo Ardi Widodo (2020) mengatakan bahwa signifier merupakan bunyi atau coretan yang bermakna. Ia adalah aspek material bahasa, yaitu apa yang dikatakan atau didengar dan apa yang ditulis atau dibaca, sedangkan signified adalah aspek mental bahasa. Secara praktis, kerangka pikir itu dapat dipetakan sebagai berikut (Gambar 1).

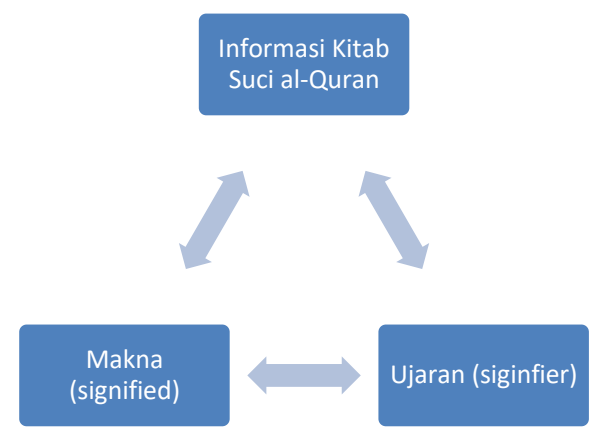

Gambar 1 : Triangulasi Kode Budaya (sumber : diolah Momon Sudarma, 2020).

Sumberdata yang digunakan bersifat sekunder, yakni karya tafsir Al-Quran yang terkait dengan objek kajian. Hal ini dimaksudkan karena alasan (1) Al-Quran merupakan kitab suci yang sudah merangsang pembacaan yang sangat kaya, (2) tersedia cukup banyak tafsir Al-Quran yang berusaha untuk menjelaskan makna-makna firman Allah Swt. Oleh karena itu, wacana ini, lebih merupakan sebuah analisis struktural dengan memanfaatkan informasi yang sudah dikemukakan pada penafsir terhadap Al- 
Quran. Pendekatan yang digunakannya, yakni analisis kritis terhadap informasi kitab suci Al-Quran pada Surat Yusuf ayat 43-49.

Nabi Yusuf AS merupakan salah satu dari 25 nabi yang wajib diketahui oleh seorang Muslim. Nabi Yusuf As berada di urutan ke-11, adalah putra Nabi Yaqub AS. Nama ini diabadikan sebagai nama sebuah surat, yaitu surat ke-12 dalam kitab suci AlQuran. Meminjam pendapat dan sindiran Hamka (1999), surat Yusuf dari kitab suci AlQuran ini, termasuk surat yang paling favorit di tengah masyarakat. Sayangnya, kepopularan atau keviralannya itu bukan disebabkan karena untuk diamalkan, tetapi dijadikan sebagai sebuah 'jampe' atau doa supaya memiliki keturunan laki-laki yang tampan. Kemudian, kisah Yusuf - Zulaikha pun, menjadi inspirasi yang luar biasa, bagi kalangan kaum sufi atau penganut tasawwuf untuk menggambarkan cinta dan keromantisannya. Ash-Shadr (2003) menyebut isah nabi Yusuf As ini, sebagai kisah terbaik (ahsanul qashash).

Salah satu penggalan sejarah Nabi Yusuf As yang perlu dicermati, adalah kemampuannya dalam menafsirkan mimpi. Kisah ini tertuang, khususnya dalam kaitannya dengan menjelaskan, menganalisis dan memprediksi potensi bencana yang akan datang, sebagai indikasi yang terungkap dalam sebuah "mimpi".

Kisah ini berawal dari mimpi Raja Mesir, Rayyan bin Al-Walid bermimpi. Kisah ini tertuang dalam firman Allah Swt dalam Surat Yusuf ayat 43-45, berikut:

43.... Raja berkata (kepada orang-orang terkemuka dari kaumnya): "Sesungguhnya aku bermimpi melihat tujuh ekor sapi betina yang gemuk-gemuk dimakan oleh tujuh ekor sapi betina yang kurus-kurus dan tujuh bulir (gandum) yang hijau dan tujuh bulir lainnya yang kering." Hai orang-orang yang terkemuka: "Terangkanlah kepadaku tentang ta'bir mimpiku itu jika kamu dapat mena'birkan mimpi."

44.... Mereka menjawab: "(Itu) adalah mimpi-mimpi yang kosong dan Kami sekali-kali tidak tahu menta'birkan mimpi itu."

45. ..Dan berkatalah orang yang selamat diantara mereka berdua dan teringat (kepada Yusuf) sesudah beberapa waktu lamanya: "Aku akan memberitakan kepadamu tentang (orang yang pandai) mena'birkan mimpi itu, Maka utuslah aku (kepadanya)." (Qs. Yusuf, 12:43-45)

Perlu diingat kembali bahwa Nabi Yusuf As pada waktu itu masih menjadi (Hamka, 1999, jilid 5:3656), tahanan politik Kerajaan Mesir. Menurut Hamka kasus ini, dapat disebut sebagai tahanan politik, karena dianggap potensial melakukan pencemaran nama baik kerajaan, khususnya terhadap istri Perdana Menteri Mesir (Al-Aziz) yang bernama Qithfir, dan istri pejabat negara pada waktu itu. Namun demikian, karena dikenal sebagai orang yang ahli dalam menafsirkan mimpi, maka kemudian kemampuannya itu dimanfaatkan oleh Raja Mesir saat itu. 
Informasi selanjutnya, dalam memperkuat pemahaman ini, dapat dikaji pada ayat 46-49 pada Quran Surat Yusuf, dengan terjemahan:

46. (setelah pelayan itu berjumpa dengan Yusuf dia berseru): "Yusuf, Hai orang yang Amat dipercaya, Terangkanlah kepada kami tentang tujuh ekor sapi betina yang gemuk-gemuk yang dimakan oleh tujuh ekor sapi betina yang kurus-kurus dan tujuh bulir (gandum) yang hijau dan (tujuh) lainnya yang kering agar aku kembali kepada orang-orang itu, agar mereka mengetahuinya."

47. Yusuf berkata: "Supaya kamu bertanam tujuh tahun (lamanya) sebagaimana biasa; Maka apa yang kamu tuai hendaklah kamu biarkan dibulirnya kecuali sedikit untuk kamu makan.

48. kemudian sesudah itu akan datang tujuh tahun yang Amat sulit, yang menghabiskan apa yang kamu simpan untuk menghadapinya (tahun sulit), kecuali sedikit dari (bibit gandum) yang kamu simpan.

49. kemudian setelah itu akan datang tahun yang padanya manusia diberi hujan (dengan cukup) dan dimasa itu mereka memeras anggur." (Qs. Yusuf, 12: 46-49)

Dengan memperhatikan rangkaian informasi kitab suci Quran tersebut, ada satu tahun yang tidak diimpikan oleh Raja Mesir, yakni tahun transisi yang dijelaskan Nabi Yusuf As. Menurut Sayid Qutb (Quthb, 2001, jilid VI:355), satu tahun yang tidak terucapkan Raja Mesir. Dalam penuturan Nabi Yusuf As (ayat 49), pada waktu itu, akan datang tahun yang padanya manusia diberi hujan (dengan cukup) dan di masa itu mereka memeras anggur. Inilah transisi menuju kebaikan dan perbaikan, dan prediksi Nabi Yusuf As. Penafsiran itu dikategorikan Sayid Qutb sebagai ilmu laduni, ilmu yang langsung diberikan Allah Swt terhadap Yusuf As. Bila distrukturasi, maka skema pemikiran Yusuf As itu, adalah data dan informasi dari mimpi, kemudian ditafsirkan. Setelah ditafsirkan, disusunlah sebuah strategi mitigasi menghadapi bencana kekeringan (hidyrometeorologi) (Gambar 2).

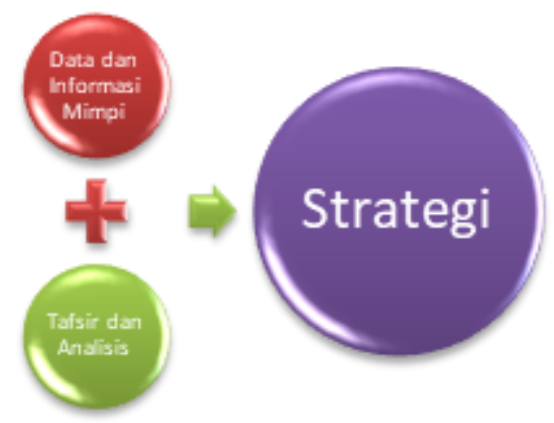

Gambar 2. Skema kontruksi pemikiran dalam kisah Nabi Yusuf As Sumber: Ilustrasi Momon Sudarma, 2020. 
Penjelasan Yusuf As., dipandang realistis dan mudah dipahami Sang Raja, kemudian firman Allah Swt ini menerangkan lagi bahwa :

Dan raja berkata: "Bawalah Yusuf kepadaKu, agar aku memilih Dia sebagai orang yang rapat kepadaku". Maka tatkala raja telah bercakap-cakap dengan Dia, Dia berkata: "Sesungguhnya kamu (mulai) hari ini menjadi seorang yang berkedudukan Tinggi lagi dipercayai pada sisi kami". (Qs. Yusuf, 12:54)

Akibat adanya kepercayaan dari Raja itulah, kemudian Nabi Yusuf As, memiliki kesempatan untuk memanfaatkan kemampuannya dalam membantu memecahkan masalah negara tersebut. Akhirnya nabi Yusuf As, berkata :

55. berkata Yusuf: "Jadikanlah aku bendaharawan negara (Mesir); Sesungguhnya aku adalah orang yang pandai menjaga, lagi berpengetahuan". (Qs. Yusuf, 12:55)

Setelah Nabi Yusuf As menjadi bendahara kerajaan, kemudian mitigasi bencana kelaparan dan kekeringan itu dilakukan, dan akhirnya, Negara Mesir saat itu bisa terhindar dari bencana. Allah Swt berfirman :

Dan demikianlah Kami memberi kedudukan kepada Yusuf di negeri Mesir; (dia berkuasa penuh) pergi menuju kemana saja ia kehendaki di bumi Mesir itu. Kami melimpahkan rahmat Kami kepada siapa yang Kami kehendaki dan Kami tidak menyia-nyiakan pahala orang-orang yang berbuat baik. Dan Sesungguhnya pahala di akhirat itu lebih baik, bagi orang-orang yang beriman dan selalu bertakwa. (Qs. Yusuf,2: 56-57).

Demikian, pengalaman nabi Yusuf As dalam mengaantisipasi bencana kekeringan dan kelaparan, sehingga mampu menyelamatkan negara dan bangsanya dari bencana yang potensi menimpa saat itu. Nabi Yusuf As merupakan salah satu figur Rasulullah (utusan Allah) yang telah memberikan contoh praktis dalam memecahkan masalah hidup dan kehidupan. Dalam kaitan ini, sikap dan tindakan Yusuf As sangat praktis dan praxis, yakni terlibat langsung dengan pemecahan masalah kehidupan bangsa dan negara saat itu. Pertama, kebutuhan akan data dan informasi yang tepat. Dalam kasus ini, data dan informasi didapat dari mimpi Raja Mesir, Ar-Rayan bin Al-Walid. Mimpi Raja Mesir ini, dijadikan bahan dasar untuk dijadikan analisis terhadap masalah yang dihadapi dan dimiliki. Ketersediaan data dan informasi yang tepat ini, digunakan untuk menyusun perencanaan. Dalam hal ini, Sayyid Ridha Ash-Shadr (2003:126) saat menjelaskan kisah Yusuf As dalam menerangkan mimpi Raja Rayyan bin Walid, menarik inspirasi bahwa takdir haruslah dihadapi dengan persiapan, atau dalam istilah lain, yakni perlu ada usaha preventif dan perencanaan mitigasi. Data dan informasi yang tepat ini akan memiliki fungsi yang penting dalam mengembangkan model managemen bencana (disaster management) (Susanto, 2006). Kedua, seorang pemimpin tidak boleh alergi meminta bantuan kepada lawan politik atau terpidana. 
Dalam kasus ini, Raja Mesir mencari penafsir mimpi, bukan kepada tim penasehat Mesir saja, melainkan juga kepada Nabi Yusuf As, yang notabene pada waktu itu masih berstatus sebagai terpidana dengan kasus 'pencemaran nama baik' istri Raja.

Pandangan menariknya lagi, sebagaimana disampaikan Qurthubi (2009) dan Wahbah Az-Zuhaili (2013) mimpi orang kafir pun bisa benar, dan bisa dimanfaatkan atau ditafsirkan oleh orang mukmin. Dalam Kitaf Tafsir Jilid 9, saat menafsirkan Surat Yusuf Qurthubi (2009) mengatakan :

"Ayat ini menjelaskan akan bolehnya menerima pendapat nonmuslim. Ayat ini sendiri lahir karena pandangan seorang kafir. Boleh, bahkan apabila sebuah urusan berkaitan dengan kepentingan orang-orang beriman. 'Tidak ada alasan menolaknya, terutama jika ayat tersebut adalah tanda kenabian Nabi Saw dan mukjizat Rasul, serta pembenaran bagi sang utusan untuk menyampaikan risalahnya dan hujjah perantara antara Allah Swt dengan hamba-hamba-Nya"

Dalam kaitan ini, sumber referensi keilmuan, Islam tidak membedakan latar belakang sosial budaya dan perbedaan agama pengembangnya. Sains, teknologi dan ilmu pengetahuan nonmuslim pun, bisa dimanfaatkan dan digunakan sebagai pengembangan wawasan dan keilmuan bagi seorang muslim. Di sinilah, sikap objektif dan terbukanya seorang muslim dalam memanfaatkan ilmu pengetahuan dan teknologi.

Dari perspektif keilmuan, informasi dan data yang dapat dikumpulkan itu, bisa berupa data pengetahuan lokal (local genius, local knowledge) seperti yang diisyaratkan dengan mimpi raja, dan juga pengetahuan rasional atau ilmiah (scientific knowledge), seperti yang dikembangkan Yusuf As.

Ketiga, Tim penasehat adalah figur yang sudah jelas memiliki rekam jejak keilmuan yang tangguh. Keterpilihan Yusuf As sebagai penafsir mimpi raja, adalah disebabkan karena selama dalam penjara, Nabi Yusuf As mampu memberikan penjelasan yang bernash dan terbukti kepada rekan-rekan yang ada di dalam penjaranya tersebut. Untuk kasus Nabi Yusuf As, Wahbah Az-Zuhaili (Az-Zuhaili, 2013:513) berpendapat bahwa kemampuan Rasulullah Yusuf As dalam menafsirkan mimpi itu, merupakan anugerah dari Allah Swt, dan masuk kategori mukjizat kenabian, sehingga memperkuat statusnya sebagai nabi dan rasul. Hemat kata, seseorang yang memiliki kompetensi tertentu, dapat memiliki kesempatan dan hak untuk mempromosikan diri. Dalam hal ini, ucapan Nabi Yusuf As, yang berbunyi “

"Jadikanlah aku bendaharawan negara (Mesir); Sesungguhnya aku adalah orang yang pandai menjaga, lagi berpengetahuan”.

Sikap realistis diperlukan dalam memecahkan kebuntuan bangsa dan negara. Keberanian Nabi Yusuf As untuk mengajukan diri merupakan pertaruhan kredibilitas dan kapabilitas terhadap ucapan dan keinginan untuk berkontribusi terhadap urusan bangsa dan negara. Sayyid Ridha Ash-Shadr (2003), menyebutnya bahwa konsep dan strategi itu hendaknya merupakan sebuah strategi yang bisa diterapkan dan dilaksanakan. Kasus penanaman tanaman pangan (gandum), merupakan contoh nyata 
dalam mitigasi bencana hydrometeorology. Menurut Mochamad Nur Ichwan (2012), model strategi Yusuf As ini, masuk kategori eko-teologi bencana.

Kredibilitas pejabat negara, perlu ditunjukkan baik dalam intelektualitas, spiritualitas, loyalitas, kepekaan, dan juga personalitas. Dalam hal ini, Nabi Yusuf As mampu menunjukkan nilai-nilai dasar serupa itu. Bahkan, sebagaimana yang dikutip Wahbah az-Zuhaili (Az-Zuhaili, 2013:496), Rasulullah Muhammad Saw menjadikannya sebagai salah satu contoh karakter yang mendapat naungan ilahi di yaumil akhir .

"Tujuh golongan manusia yang akan mendapatkan naungan Allah pada hari dimana tidak terdapat naungan kecuali naungan-Nya: Imam (pemimpin) yang adil, pemuda yang selalu beribadah kepada Allah, orang yang hatinya selalu bergantung dengan masjid ketika keluar dari masjid hingga dia kembali lagi, dua orang laki-laki yang saling mencintai karena Allah, keduanya berkumpul dan berpisah karena Allah, orang yang bersedekah kemudian menyembunyikan sedekahnya sehingga tangan kirinya tidak mengetahui apa yang disedekahkan oleh tangan kanannya, orang laik-laki yang berkata ketika dirayu perempuan yang memiliki kedudukan dan kecantikan, 'sungguh aku takut kepada Allah', dan orang laki-laki yang berzikir kepada Allah dalam kesendirian dan air matanya berjatuhan."

Buah dari kontribusi yang besar itulah, kemudian Nabi Yusuf As, mendapatkan posisi yang luar biasa, baik di dunia maupun di akhirat. Di dunia, Nabi Yusuf As, termasuk elit politik ring satu, yang memiliki posisi yang dekat dengan raja, kemudian secara formal memiliki jabatan tertinggi, yakni sebagai makinun amin, jabatan tertinggi dan terpercaya. Bahkan, jabatannya itu sangat terbuka, istilah Al-Quran, Nabi Yusuf As mendapat peluang untuk memilih jabatan min haitsu yahsya, tempat apapun dan di manapun yang disukainya. Sementara di akhirat, Allah Swt berjanji, 'Kami melimpahkan rahmat Kami kepada siapa yang Kami kehendaki dan Kami tidak menyianyiakan pahala orang-orang yang berbuat baik. Dan Sesungguhnya pahala di akhirat itu lebih baik, bagi orang-orang yang beriman dan selalu bertakwa".

Keempat, tak pelak lagi, tawil merupakan salah satu metode keilmuan, atau lebih akademisnya, salah satu epistemologi keilmuan. Model ilmu ini, tidak sekedar empiris atau rasionalis, tetapi menyertakan keikhlasan dan kebersihan hati, sehingga mendapatkan illmu laduni, seperti yang dimiliki Rasulullah Yusuf As.

Hamka dalam Tafsir Al-Azharnya, memperkenalkan metode penafsiran mimpi yang dikedepankan oleh Sigmund Freud. Pendekatan psikoanalisa, itulah sebutan model penalaran serupa ini. Meminjam penjelasan Wahbah az-Zuhaili (Az-Zuhaili, 2013:512), Ibnu Abbas mengatakan bahwa mimpi itu adalah dua jenis, yakni mimpi yang benar dan mimpi yang bathil. Terkait hal ini, ada yang mengartikan mimpi sebagai bunga tidur. Akan tetapi, sebagai bunga tidur, mimpi itu bisa hadir dalam beberapa bentuk, (1) karena pengaruh fisik, misalnya kelelahan, sakit atau demam, maka seseorang potensial mengalami mimpi, (2) proyeksi emosi pribadi, sifatnya subjektif, sesuai dengan 
khayalan diri sendiri, dan (3) mimpi ruhani, yang bermuatan nilai, inspirasi atau ilham perlu ditafsirkan dan ditindaklanjuti. Untuk kasus Raja ar-Rayan bin al-Walid, masuk dalam kategori ketiga, dan menjadi mimpi yang perlu penafsiran secara tepat untuk memahaminya.

Bila dicermati dengan seksama, pendekatan mitigasi bencana yang dikembangkan Nabi Yusuf As, meliputi (1) penyusunan rencana kerja secara kelembagaan (kerajaan), (2) menyusun strategi penguatan pangan, dengan teknik peningkatan produksi (menanam gandum) dan investasi (menyimpan gandum), (3) penetapan tim manajemen mitigasi, atau personalia yang tepat ahli dan tetap waktu (ilustrasi nabi Yusuf jadi Bendahara).

\section{SIMPULAN}

Kisah Nabi Yusuf As dapat dijadikan contoh, setidaknya sebagai sumber inspirasi dalam memecahkan masalah lingkungan, ekonomi lingkungan dan strategi pemberdayaan sumberdaya manusia kebangsaan. Komunikasi dan kerjasama yang dilakukan Yusuf As dan Raja Ar-Rayyan bin Al-Walid, merupakan isyarat bahwa dalam memecahkan masalah kebangsaan, atau ekonomi lingkungan, perlu ada kerjasama antara ilmuwan-agama (Yusuf As) dengan penguasa (Raja Ar-Rayyan bin Al-Walid). Bahkan, Raja Ar-Rayyan bin Al-Walid mampu menunjukkan sikap kenegarawanan dengan mengedepankan kepentingan bangsa. Sikap ini menggambarkan bahwa perbedaan politik, kepentingan atau urusan pribadi, hendaknya tidak menghapuskan sikap adil dalam memperlakukan orang. Di sinilah, etika akademik dan etik penguasa bersentuhan, sehingga melahirkan sebuah kemitraan yang positif dalam menjaga keberlangsungan bangsa dan negara. Melalui kisah ini pula, Yusuf As sudah memberikan contoh sikap dalam pengembangan model eko-teologi (teologi lingkungan), khususnya dalam kaitannya dengan mitigasi bencana.

\section{DAFTAR PUSTAKA}

Al-Alusi, M. S. (2014). Al-Quran dan Ilmu Astronomi ( penerjemah K. A. Irsyad, Ed.). Jakarta: Pustaka Azam.

Al-Qurthubi, I. (2009). Tafsir Qurthubi (terjemahan). Jilid 9. Jakarta: Pustaka Azam.

Ali, A. M. (1991). "Metodologi Ilmu Agama Islam", Metodologi Penelitian Agama: Suatu Pengantar (hal. 41-58).

Ash-Shadr, S. R. (2003). Kisah Terbaik: Kisah dan Pelajaran Kehidupan Dibalik Sejarah Nabi Yusuf As. (terjemahan). Jakarta: Penerbit Lentera.

Az-Zuhaili, W. (2013). Tafsir al-Munir (terjemahan). Jilid 6. Jakarta: Gema Insani Press. HAMKA. (1999). Tafsir Al-Azhar, (ed. digital). Jilid 5. Singapure: Pustaka Nasional.

Ichwan, M. (2012). "Eko-Teologi bencana, Aktivisme Sosial dan Politik Kemaslahatan",. dalam A. Baiquni (Ed.), Agama, Budaya dan Bencana (hal. 19-23). Mizan - UGM Press.

Ma'arif, A. (1991). "Posisi Sentral al-Quran dalam Studi Islam",. dalam Metodologi Penelitian Agama: Suatu Pengantar, (hal. 125-134). Jogjakarta: Tiara Wacana.

Nasr, S. H. (1997). Sains dan Peradaban dalam Islam. Bandung: Mizan.

Qutb, S. (2001). Fi Zhilalil Quran. Jilid VI. Jakarta: Gema Insani Press. 
Shihab, M. Q. (1991). "Posisi Sentral al-Quran dalam Studi Islam.” dalam Metodologi

Penelitian Agama : Suatu Pengantar (hal. 135-148.). Jogjakarta: Tiara Wacana.

Susanto, A. (2006). Disaster Management di Negeri Rawan Bencana. Jakarta: Aksara Grafika Pratama.

Widodo, S. (2020). Analisis Struktural Dalam Kajian Al-Quran (Surat Yusuf).

\section{HASIL DISKUSI}

Tidak ada pertanyaan 